\title{
A Reforma do Sistema de Saúde no Brasil e o Programa de Saúde da Família ${ }^{1}$
}

\author{
ANA LUIZA D'ÁVILA VIANA \\ MARIO ROBERTO DAL POZ
}

O texto examina as etapas de formulação e implementação do Programa de Saúde da Família, indicando as estratégias esboçadas e analisando os resultados, com vistas a extrair lições para o aperfeiçoamento da política de saúde no Brasil. Foram identificados três modelos de implantação do programa: Modelo Regional, Modelo Singular e Modelo Principiante. O primeiro se caracteriza pelo desenvolvimento regional do programa, sendo fortemente influenciado por uma política estadual de apoio à mudança nas práticas assistenciais; o segundo desenvolve uma experiência singular, sem envolvimento de outras esferas de governo; e o terceiro se desenvolve de forma incipiente e incerta.

Palavras-chave: Programa de Saúde da Família; reforma em saúde; política pública. 


\section{Antecedentes ${ }^{4}$}

Nos estudos sobre os processos de reforma dos sistemas de saúde deve-se, segundo France (1997), distinguir dois tipos de reforma: big bang e incremental. As reformas do tipo big bang são as que introduzem modificações expressivas e significativas no funcionamento do sistema de saúde, de forma rápida (em curto espaço de tempo) e pontual. As reformas incrementais, ao contrário, se baseiam em pequenos ajustamentos sucessivos.

Desta forma, a reforma brasileira da saúde, de 1988, pode ser considerada de tipo big bang, pois introduziu mudanças substantivas no modo de operação do sistema. A reforma do modelo de assistência pública à saúde ocorreu com a criação do Sistema Único de Saúde (SUS).

Esse novo modelo, inscrito na própria Constituição brasileira de $1988^{5}$ definiu o princípio do universalismo para as ações de saúde, a descentralização municipalizante e um novo formato organizativo para os serviços, sob a lógica da integralidade, da regionalização e da hierarquização, com definição de porta de entrada. Além disso, as ações preventivas e curativas passaram a ser responsabilidade dos gestores públicos.

Três características definem o novo modelo: a criação de um sistema nacional de saúde; a proposta de descentralização (o gestor do sistema será o executivo municipal); e a criação de novas formas de gestão, que incluem a participação de todos os atores envolvidos com a política (prestadores de serviços, trabalhadores, gestores e usuários).

A implementação do SUS se iniciou nos anos 90, após a criação da Lei Orgânica da Saúde, e de várias normas e portarias emitidas pelo Ministério da Saúde - as Normas Operacionais Básicas (NOBs) - como instrumentos de regulamentação do sistema. Entretanto, desde o início da implantação do SUS, vários problemas se colocaram para sua operacionalização, dos quais se destacam: o financiamento das ações de saúde; a definição clara de funções para os três entes governamentais (federal, estadual e municipal); as formas de articulação público/privado no novo modelo de organização dos serviços; e a resistência do antigo modelo assistencial - baseado na doença e em ações curativas individuais - a uma mudança mais substantiva nas práticas assistenciais.

Paralelamente, o País atravessava um período de incertezas em sua política econômica (só controlada a partir de 1994, através de um novo plano de 
estabilização), havendo graves desajustes em suas finanças públicas e oscilações em suas taxas de crescimento. Assinale-se que a proposta de ajuste fiscal adotada pelo Brasil repercutiu negativamente no financiamento destinado à saúde, tendo em vista que o gasto público nessa área decresceu no início da década de 90 e só se recuperou em 1995/96.

Do ponto de vista demográfico, o País atravessava um período de mudanças radicais, com declínio de crescimento populacional e da taxa de fecundidade. A tendência detectada para as próximas décadas foi de crescimento nulo, ou até negativo, para os grupos etários mais jovens, crescimento decrescente para as faixas de idade adulta, e taxas crescentes para o grupo de terceira idade. Esse novo perfil incidiu de forma bastante aguda na saúde, tendo em vista que exigiu e exige, cada vez mais, ações voltadas para a idade adulta e para a terceira idade, sabidamente de maiores custos.

Do ponto de vista epidemiológico, segundo Patarra:

“[...] os especialistas em saúde pública denominaram transição epidemiológica a evolução gradual dos problemas de saúde caracterizados pela alta prevalência de mortalidade por doenças infecciosas, para um estado em que passam a predominar doenças não-infecciosas (ou também crônico-degenerativas); por tratar-se de enfermidades de longa duração, acumulam-se na população, ocorrendo uma combinação paradoxal de declínio da mortalidade com aumento da morbidade" (PATARRA, 1995).

Pode-se afirmar que as mudanças demográficas e epidemiológicas se entrecruzam, no Brasil, sendo que a transição demográfica tem nítida relação com a transição epidemiológica, em virtude da rápida transformação da estrutura etária da população.

No entanto, o quadro de transição epidemiológica encontrado em países periféricos, em especial na América Latina, é mais complexo: na medida em que persistem os padrões relacionados a doenças infecto-contagiosas, elevamse as chamadas crônico-degenerativas, além do crescimento das causas externas (homicídios, acidentes etc.). Tais mudanças alteraram significativamente a demanda por serviços de saúde, e exigiram - e exigem - a adoção de novos tipos de ações, equipamentos e intervenções.

Esse contexto, formado por múltiplos problemas, de diferentes ordens, incidiu de forma bastante aguda na demanda e na oferta de saúde, e passou a 
ser denominado, nos anos 90, de crise da saúde. A crise da saúde é uma das razões mais fortes para o início, a partir de 1995, da reforma da reforma da saúde no Brasil, ou do processo de reforma incremental do SUS.

\section{O Processo de Reforma Incremental': Conceitos e Approach Metodológico}

A década de 90, em vários países, caracteriza-se por ser a década das reformas (tanto de tipo big bang quanto incremental) dos sistemas nacionais de saúde. São reformas diferentes daquelas operadas no final dos anos 70 e 80 , mas como resposta, ainda, a uma mesma conjuntura ou a um mesmo problema de base ${ }^{7}$.

As propostas para a área da saúde, nos anos 90, podem ser resumidas em três grandes blocos, que constituem o que se poderia chamar de agenda global da saúde: a separação das funções de provisão e financiamento das ações de saúde; a inclusão de mecanismos de mercado através da competição administrada; e a ênfase na efetividade clínica (resultado das ações de saúde). Pode-se agregar, ainda, um outro tipo de proposta, que ainda não está tão disseminada quanto as demais, mas que certamente será um dos eixos de futuras reformas: mudanças na concepção de saúde e no papel dos usuários nos sistemas de saúde (reforço da cidadania) ${ }^{8}$.

Assim, muitos países iniciaram a década tentando implementar um ou outro ponto dessa agenda, através de processos diferentes, tendo em vista as diferentes conjunturas nacionais e os diferentes processos de constituição e operação dos sistemas de saúde. Definiram-se, assim, práticas localizadas vis$\grave{a}$-vis conceitos globais (ou uma agenda global), tema, inclusive, de um artigo de dois cientistas sociais (BJÖRKMAN \& ALTENSTETTER, 1997), que compararam as experiências internacionais de reforma nessa década e avaliaram os resultados encontrados.

Segundo esses mesmos autores, a implementação da agenda de reforma e os resultados obtidos dependeram do comportamento de três variáveis: exigências econômicas, interesses organizados e dimensão política. Essas variáveis irão explicar tanto a reforma (implantação dos propósitos enunciados) quanto a não-reforma (não-implementação dos propósitos). Dessa forma, os autores citados procuram responder como as estruturas institucionais domésticas e os interesses organizados favoreceram ou obstaculizaram a ação dos atores 
no processo de formulação e implementação de propostas e políticas de reforma. Esse approach metodológico sugerido por Bjorkman e Altenstetter será utilizado na análise do processo de reforma incremental do SUS.

Assim, convém precisar o que se está chamando de reforma da reforma, ou melhor, de reforma incremental: define-se o processo de reforma incremental como um conjunto de modificações no desenho e operação da política. O conjunto de mudanças pode ocorrer, separada ou simultaneamente, nas formas de organização dos serviços (mudanças nos sistemas e nas unidades prestadoras), nas modalidades de alocação de recursos e formas de remuneração das ações de saúde ou, ainda, no modelo de prestação de serviços (modelo assistencial).

Foram selecionadas três variáveis, por se considerar que uma mudança em qualquer uma delas terá repercussões importantes sobre as demais. No caso brasileiro, considera-se que as mudanças no modelo assistencial operadas dentro do SUS, por conta de dois novos programas -Programa de Agentes Comunitários de Saúde (PACS) e Programa de Saúde da Família (PSF) -, estão provocando alterações tanto nas modalidades de alocação de recursos e formas de remuneração das ações de saúde, quanto na forma de organização dos serviços. Dessa forma, o PSF constitui uma estratégia de reforma incremental do sistema de saúde no Brasil, tendo em vista que o programa aponta para mudanças importantes na forma de remuneração das ações de saúde (superação da exclusividade do pagamento por procedimentos), nas formas de organização dos serviços e nas práticas assistenciais no plano local, e, portanto, no processo de descentralização.

A emergência de uma nova norma operacional do Ministério da Saúde (NOB-96) - que modifica a forma de transferência de recursos interinstâncias de governo e a forma de pagamento dos serviços de saúde, no sentido da variação das modalidades de transferência de recursos (não mais tão-somente por procedimentos) -, além de novas práticas que estão se desenvolvendo no setor público de saúde (principalmente na área hospitalar, como a adoção de novas formas de gerência mais flexíveis, alternativas à administração direta) constituem também elementos de reforço ao processo de reforma. São ainda indicativos da constituição de novos instrumentos indutores, como no caso do Programa de Saúde da Família, do processo de reforma incremental do sistema público de saúde. 
Por isso, pode-se dizer que a partir de 1995/96, com a implementação já acelerada e em nível nacional desses novos programas ${ }^{9}$, das novas práticas gerenciais e da emergência do processo de formulação da nova norma operacional (NOB-96) ${ }^{10}$, tem início o período de reforma incremental do SUS.

Obviamente esses processos se entrecruzam e produzem efeitos sinérgicos e, por isso mesmo, se constituem - mais ainda, se configuram como instrumentos do processo de reforma (incremental) do sistema de saúde, no Brasil. O modelo proposto - que enfoca a reforma, tendo em vista o comportamento das três variáveis (exigências econômicas, interesses organizados e dimensão política) - será efetuado ao longo da análise da formulação do PSF.

Finalmente, a análise da formação privilegiou a identificação das fases dessa etapa da política, dos atores presentes em cada fase e das alianças que estes estabeleceram em apoio/oposição ao programa. Foram entrevistados nove atores-chave do processo de formulação da política e analisados todos os documentos elaborados pelo Ministério da Saúde, no período ${ }^{11}$.

\section{As Estratégias de Implantação da Reforma}

\subsection{Antecedentes do Programa de Saúde da Família: o Programa de Agentes Comunitários de Saúde}

A história do Programa de Saúde da Família (PSF) tem início quando o Ministério da Saúde forma o Programa de Agentes Comunitários de Saúde (PACS), em 1991. A partir daí começou-se a enfocar a família como unidade de ação programática de saúde e não mais (tão-somente) o indivíduo, e foi introduzida a noção de área de cobertura (por família).

$\mathrm{Na}$ verdade, o ministério institucionalizou, nesse momento, as experiências de práticas em saúde com agentes comunitários, que já vinham se desenvolvendo de forma isolada e focalizada em diversas regiões do País (nos estados do Paraná, Mato Grosso do Sul e Ceará, neste se constituindo como uma política estadual).

Pode-se afirmar, então, que o PACS é um antecessor do PSF, pois uma das variáveis importantes que o primeiro introduziu e que se relaciona diretamente com o segundo é que pela primeira vez há um enfoque na família e não no indivíduo, dentro das práticas de saúde. O programa também introduziu uma 
visão ativa da intervenção em saúde, de não "esperar" a demanda "chegar" para intervir, mas de agir sobre ela preventivamente, constituindo-se, assim, em instrumento real de reorganização da demanda. Além disso, outro diferenciador são as concepções de integração com a comunidade e de um enfoque menos reducionista sobre a saúde, não centrado apenas na intervenção médica. Sublinhe-se que todos esses elementos serão centrais para a construção do Programa de Saúde da Família, porque constituem a essência (da concepção) de sua intervenção.

O PACS foi formulado tendo como objetivo central contribuir para a redução da mortalidade infantil e mortalidade materna, principalmente nas regiões Norte e Nordeste, através de extensão de cobertura dos serviços de saúde para as áreas mais pobres e desvalidas. Porém, a partir da experiência acumulada pelo estado do Ceará com o Programa de Agentes Comunitários ali implantado, houve a percepção, pelo próprio Ministério da Saúde, de que os agentes poderiam também ser peça importante para a organização do serviço básico de saúde no município.

Dessa forma, duas questões tomaram relevância no processo de implantação do PACS: a escolha do agente (envolvendo questões como processo seletivo, capacitação, avaliação etc.) e as condições institucionais da gestão da saúde no nível local (grau de participação dos usuários; formação dos conselhos de saúde; grau de autonomia da gestão financeira; recursos humanos disponíveis; capacidade instalada disponível etc.).

Por isso, pode-se afirmar que, pelo fato de o Programa de Agentes Comunitários ter tomado essa forma, ele não constituiu, então, apenas mais um programa vertical do Ministério da Saúde (uma ação paralela ao sistema de saúde). Foi também um braço auxiliar na implementação do SUS e na organização dos sistemas locais de saúde. Porque no momento em que a adesão do município ao PACS passou a exigir certos requisitos - como o funcionamento dos conselhos municipais de saúde, a existência de uma unidade básica de referência do programa, a disponibilidade de um profissional de nível superior na supervisão e auxílio às ações de saúde e a existência de fundo municipal de saúde para receber os recursos do programa - este se tornou, sobretudo, um instrumento de (re)organização dos modelos locais de saúde.

Ressalte-se, entretanto, que não foi apenas o fato de ter definido essa estratégia de implantação que fez do programa um instrumento de (re)organização do SUS, mas também o grau de articulação que esse desenvolveu com os 
diferentes níveis do sistema (estadual e municipal), além do papel desempenhado pelos atores participantes do processo de implementação do programa (agentes e comunidade). Esse processo se consolidou em março de 1994, quando o mecanismo de financiamento do PACS se inseriu no pagamento por procedimentos operado pelo SUS, ou seja, a tabela do Sistema de Informação Ambulatorial (SIA/SUS). Por último, cabe assinalar que o êxito do PACS impulsionou a formulação do PSF, como foi repetidamente alertado por todos os entrevistados.

\subsection{O Programa na Fundação Nacional de Saúde, operado através de Convênio}

O Programa de Saúde da Família foi concebido a partir de uma reunião ocorrida nos dias 27 e 28 de dezembro de 1993, em Brasília, sobre o tema Saúde da Família, convocada pelo gabinete do ministro da Saúde (Dr. Henrique Santillo). Essa reunião foi a resposta do ministério a uma demanda de secretários municipais de Saúde, que queriam apoio financeiro para efetuar mudanças na forma de operação da rede básica de saúde (expansão do programa dos agentes para outros tipos de profissionais).

Participaram dessa reunião técnicos do Ministério da Saúde, de secretarias estaduais, secretários municipais de Saúde, consultores internacionais e especialistas em atenção primária ${ }^{12}$. Foi um momento importante, pois agregou técnicos das regiões Sudeste e Sul do País, e as experiências inovadoras nessas regiões, rompendo com o isolamento do PACS, isto é, com o seu confinamento às regiões Norte e Nordeste.

É importante ressaltar que até aquele momento era o UNICEF que se mostrava mais interessado em apoiar programas de atenção básica. A OPAS, ao contrário, se restringia às propostas de desenvolvimento de sistemas locais de saúde (distrito sanitário) e de referências bastante vagas sobre atenção primária. $\mathrm{O}$ aspecto que influenciou a participação diferenciada das agências internacionais foi, como se sabe, a estrutura dessas instituições: a estrutura interna da OPAS é bastante pesada e burocrática, ao contrário do UNICEF, que é mais leve e flexível.

Em todas as entrevistas foi ressaltado o papel de um técnico do UNICEF (Halim Antônio Girade) como o grande apoiador do Programa de Saúde da Família, fazendo a ponte entre técnicos, gestores e o ministro da Saúde, e apoiando 
também financeiramente o desenvolvimento do programa, através do PNUD. Ressalte-se que toda a equipe de coordenação do programa no Ministério da Saúde foi contratada pelo PNUD, não sendo, até hoje, formada por funcionários de carreira do ministério.

A reunião de dezembro esteve assentada na discussão de uma nova proposta. Partia-se do êxito do PACS, por um lado, e da necessidade de incorporar novos profissionais, para que os agentes não funcionassem de forma isolada, por outro. Cabe salientar que a experiência do Ceará - de supervisão do trabalho do agente pelo enfermeiro ${ }^{13}$ - foi um primeiro passo no processo de incorporação de novos profissionais. Outro referencial importante nessa reunião foi a experiência de Niterói, com o Programa Médico de Família.

Dessa maneira, ao final da reunião emergiu a proposta do Programa de Saúde da Família e foi criada, na Fundação Nacional de Saúde, dentro do Departamento de Operações, a Coordenação de Saúde da Comunidade (COSAC), uma gerência específica para o programa. Essa coordenação agregava três programas: o de Agentes Comunitários, o da Saúde da Família e o de Interiorização do SUS.

O primeiro documento do programa data de setembro de 1994 (BRASIL, 1994). Suas diretrizes foram concebidas a partir da reunião de dezembro de 1993 e foram citados ainda todos os participantes da reunião. A concepção do programa, segundo esse documento, é de fazê-lo um instrumento de reorganização do SUS e da municipalização, definindo que sua implantação ocorrerá, prioritariamente, nas áreas de risco. É utilizado o Mapa da Fome, do Instituto de Pesquisas Econômicas Aplicadas (IPEA), como critério de seleção para as áreas de risco.

O mecanismo de financiamento desse período é o convênio firmado entre Ministério da Saúde, estados e municípios, com exigências de contrapartidas e critérios de seleção de municípios (áreas citadas pelo Mapa da Fome), obedecendo aos seguintes fatores: interesse da comunidade, necessidades locais de saúde, oferta de serviços, estudo da demanda, existência de apoio diagnóstico terapêutico e disposição da administração municipal.

Para a assinatura do convênio exige-se que o Conselho Municipal de Saúde esteja em funcionamento, assim como o Fundo Municipal de Saúde ${ }^{14}$. Entretanto, como se sabe, o mecanismo convenial é bastante limitado, burocrático e pouco flexível, e se choca com os propósitos descentralizantes do próprio 
sistema de saúde. Dessa forma, desde então ficaram claros, para os técnicos do ministério, os limites de implantação do programa (dada a forma convenial de transferir recursos) e a necessidade de rompimento com esse modelo.

\subsection{O Programa na Secretaria de Assistência à Saúde (SAS), operado através do SIA-SUS}

Em 1995, quando o ministro Adib Jatene assumiu o Ministério da Saúde, o programa foi transferido da Fundação Nacional de Saúde para a Secretaria de Assistência à Saúde (SAS). Essa transferência significou um rompimento com a idéia de programa vertical, operado através de convênio (tradição dos programas verticais da Fundação Nacional de Saúde), sinalizando sua maior importância dentro do ministério e um outro tipo de institucionalização do PSF.

Foram apontadas, pelos entrevistados, como razões importantes para que o ministro tivesse "encampado" o programa: o sucesso do PACS, não só em resultados, como também no desenvolvimento de novas práticas e novas abordagens profissionais (agente com supervisão de enfermagem); a experiência do Programa Médico de Família e a implantação da estratégia do Comunidade Solidária (que na área da saúde selecionou o PACS e o PSF como instrumentos de consecução de suas estratégias). O próprio ministro apontou, ainda, a experiência do Programa Metropolitano de Saúde ${ }^{15}$ - realizado em São Paulo, na década de 80, formulado quando ainda era secretário estadual de Saúde como um antecedente do novo modelo proposto pelo PSF.

A partir do momento em que o programa foi transferido para a SAS, começaram as discussões para que fosse remunerado pela tabela de procedimentos do SIA-SUS (superando a forma convenial ${ }^{16}$ ), o que ocorreu nos primeiros dias de janeiro de $1996^{17}$. Assinale-se que as remunerações do PSF são diferenciadas: a consulta do PSF equivale ao dobro da consulta do SUS $^{18}$. Cabe assinalar ainda que o programa também foi um diferenciador nas discussões dos tetos de transferência de recursos para os estados.

O PSF começa então a perder o caráter de programa e passa a ser um (re)estruturador dos serviços, isto é, passa a ser (mais) claramente um instrumento de (re)organização ou (re)estruturação do SUS, porque se deseja que este sirva como exemplo de um novo tipo de assistência distinto do modelo dominante, assim descrito pelo documento oficial do programa de março de 1996. 
A Reforma do Sistema de Saúde no Brasil...

\begin{abstract}
"Baseado na doença, atuando exclusivamente sobre a demanda espontânea, com ênfase na medicina curativa, tratando o indivíduo como objeto de ação, com baixa capacidade de resolver os problemas de saúde, com saber e poder centrado no médico, geralmente limitado à ação setorial, com desvinculação do pessoal de serviço com as comunidades, e de relação custo-benefício desvantajosa" (BRASIL, 1996).
\end{abstract}

Nesse período, são dois os modelos de assistência em vigência no SUS: o tradicional e o da família, associado ao dos agentes. Porém, com remuneração diferenciada para o segundo, para pressionar sua expansão e sua adoção, de forma exclusiva, nas áreas de maior risco e junto às populações mais carentes.

Assinale-se que, a partir de 1996, o PSF começa a ter melhor integração com o PACS, o que aponta para uma fusão dos dois programas, pois suas operações podiam ser combinadas, já que a equipe de saúde da família inclui o agente comunitário.

Cabe ressaltar, por último, que o programa foi um instrumento de pressão no sentido da habilitação proposta pela NOB- $93^{19}$ (e do ritmo de sua implantação, em 1994), pois as portarias da SAS ${ }^{20}$ instituíram que só poderiam ser cadastrados no SIA-SUS, como unidades do PSF, ambulatórios localizados em municípios enquadrados em uma das modalidades previstas por essa norma.

Como se sabe, a remuneração por procedimentos também é limitada, pois não pode ser estendida a todos os tipos de ações. No entanto, algumas atividades são mais bem remuneradas por outros tipos de critérios, como pagamento per capita. Podem ser citadas as atividades de prevenção, educação em saúde etc. Dessa forma, o programa evidenciou, para os técnicos do ministério, os limites dos pagamentos por procedimentos e a necessidade de combinar diferentes tipos de remuneração.

\title{
3.4. O Programa na NOB-96 e no REFORSUS, operado através da transferência per capita (Piso da Atenção Básica - PAB)
}

A partir do Programa de Saúde da Família começaram as discussões para uma mudança nos critérios de distribuição de recursos, de forma a romper com a exclusividade do pagamento por procedimentos. O PSF evidenciou que determinadas atividades não podem ser remuneradas por procedimentos, adaptando-se melhor a uma remuneração de tipo per capita. 
Assim, o PSF foi peça importante para as mudanças propostas pela NOB-96. Por essa nova Norma, foi criado o Piso da Atenção Básica (PAB), que previa remuneração per capita para que os municípios desenvolvessem ações básicas de saúde (parte fixa do PAB), além de recursos adicionais para aqueles que estivessem implementando o PSF (programa que constitui a parte variável do $\mathrm{PAB}$, entre outros).

Está previsto acréscimo de até $\mathrm{R} \$ 21$ mil por ano, para cada equipe instalada do PSF, dependendo do número de pessoas atendidas por cada uma ${ }^{21}$. Estão previstos, também, acréscimos para os municípios que estiverem implantando o PACS (programa que constitui a parte variável do PAB, entre outros), no valor de $\mathrm{R} \$ 1.500,00$ por ano, por agente ${ }^{22}$. Cabe salientar que a parte fixa do $\mathrm{PAB}$ varia de $\mathrm{R} \$ 10,00$ a $\mathrm{R} \$ 18,00$ por habitante/ano ${ }^{23}$.

Esse tipo de incentivo deverá ocasionar uma rápida expansão do programa e a definição de sua entrada no sistema municipal de saúde. De certa forma, a tendência é que o PSF se torne um programa para as populações mais deprimidas socialmente e continue o modelo antigo em algumas áreas, de pouco risco, dentro dos municípios. Entretanto, em municípios carentes, ele pode vir a ser o modelo único de assistência.

No documento de 1996, citado acima, o programa já é definido como uma estratégia de reforma do modelo de assistência do SUS, e é dito que o modelo tradicional impôs um descompasso entre os princípios e objetivos do SUS e a realidade concreta de implantação do sistema de saúde. Outra medida importante desse período foi a aproximação com a universidade, no sentido da formação e treinamento dos recursos humanos requeridos pelo programa, que irão se constituir, no ano de 1997, nos pólos de capacitação ${ }^{24}$.

O PSF remunera o médico diferenciadamente, para atrair melhores profissionais; porém, o sistema formador não está orientado para a formação de médicos generalistas, o que dificulta a contratação desse tipo de profissional e a expansão do programa. Os pólos deverão, então, solucionar esse entrave, de forma inclusive a estimular uma mudança nos currículos das escolas médicas. Por outro lado, reforçam o papel dos estados na implementação do programa e podem atuar como mecanismo de pressão para uma maior participação dessa instância de governo nos rumos do PSF. O programa foi incorporado, ainda, ao Projeto REFORSUS, do Banco Mundial. Serão privilegiadas as unidades básicas de saúde do PSF para os investimentos financiados por esse projeto. Todos os 
incentivos criados devem ocasionar maior expansão do programa e redefinição do modelo assistencial do SUS.

Por último, cabe assinalar as novas metas estipuladas para o PSF: expansão de 847 equipes para 3.500; e de 850 mil para 3,5 milhões de famílias ${ }^{25}$.

\section{O Papel do Programa Comunidade Solidária ${ }^{26}$ o o Programa de Saúde da Família como uma das estratégias de atuação}

O Comunidade Solidária (CS) foi um importante instrumento de legitimação e expansão do grau de visibilidade do PSF, além de ter sido o canal de articulação da saúde com outras áreas (trabalho, previdência, saneamento etc.). Por outro lado, facilitou a adoção do PSF pelos estados, tendo em vista que em cada um o CS possui um representante que mantém contato direto com o governador: assim, os coordenadores nos estados pressionaram, muitas vezes, como salientado na entrevista com a secretária executiva do CS, para a adoção, pelos estados e municípios, dos programas por ele encampados.

O fato de o CS ter eleito o PACS e o PSF (a participação do Ministério da Saúde no programa) - além do Programa de Redução da Mortalidade Infantil (PRMI), e os programas da área da saúde que deveriam ser implantados nos municípios carentes - deu ao PSF maior visibilidade e o legitimou dentro do próprio ministério.

\section{Atores: o PSF como construtor de novas alianças na saúde (gestores locais, técnicos externos e comunidade)}

O PSF evidenciou um novo tipo de aliança na política de saúde: de gestores locais (secretários municipais e técnicos do sistema local), com técnicos externos à área da saúde (como os técnicos do Comunidade Solidária e de organismos internacionais, como o UNICEF, e de países que desenvolvem práticas de saúde da família, como Canadá e Cuba), e com as associações da comunidade. Tal aliança se constituiu "em cima" do desenho da política, isto é, da proposta do programa de superação dos modelos tradicionais de operar ações de saúde (inovações nos tipos de contratos de profissionais, nos perfis profissionais, nos tipos de remuneração, nas práticas etc.), apoiando-se mais nas comunidades (objetos das ações), ao envolvê-las na política de maneira distinta. Assim, foi possível desenvolver novos tipos de parcerias - nacionais e 
internacionais - baseadas no espaço local, no município e no aprofundamento da descentralização. Esta é vital para o estabelecimento dessa aliança.

As antigas alianças que se estabeleceram usualmente na política de saúde (políticos, médicos e construtores de obras públicas), no nível local, foram superadas quando o programa iniciou sua implementação nos municípios, pois ele mobilizou mais as associações privadas da comunidade do que a corporação médica (inclusive porque não está centrado na figura do médico), podendo, muitas vezes, ser operado através do auxílio de consultores e técnicos internacionais. Cabe salientar que essa aliança se estabeleceu na fase de formulação do programa, pois foi, de certa forma, a que se desenvolveu ao longo da implantação do PACS. Assinale-se que a reunião de dezembro de 1993 contou com técnicos internacionais e gestores locais, que vinham respaldados por gestões exitosas na área da saúde.

Por último, sublinhe-se que esse novo tipo de aliança foi suficientemente forte para neutralizar os opositores do programa: as corporações profissionais - Conselhos Federais de Medicina e de Enfermagem, além da Associação Brasileira de Enfermagem, preocupados em garantir o mercado de trabalho dos profissionais médicos e de enfermagem; a Pastoral da Saúde - as comunidades eclesiais desenvolviam programas de agentes comunitários e se opuseram ao cadastramento das famílias pelas unidades de saúde do programa; e alguns gestores estaduais.

As comunidades organizadas, por sua vez, exerceram, em muitos locais, pressão direta em favor da continuidade do programa, pois muitas vezes este é abandonado quando tem início uma nova gestão (estadual ou municipal). Essa nova tríade de apoio político ao programa, formada a partir da formulação do PSF, tem ainda, na atuação dos Conselhos Municipais de Saúde, um canal importante de expressão, pois o conselho reforça a tríade e o programa reafirma o espaço de autonomia do conselho.

\section{Concepções Envolvidas com o PSF}

\subsection{Práticas focalizadas dentro do universalismo}

O programa vem-se expandindo de forma focalizada, à medida que são selecionadas, para sua implantação, áreas e populações de risco que podem, inclusive, corresponder a quase $80 \%$ da população de um município. Essas 
experiências de focalização dentro do universalismo evidenciam que se pode ter práticas focalizadas dentro de uma política universal e que não há necessariamente conflito entre focalização e universalização, isto é, os dois conceitos não precisam ser excludentes.

A formulação do PSF foi fruto, inclusive, do sucesso de práticas (anteriores) focalizadas dentro da política universal, e que constituíram instrumentos de reorganização e reestruturação do próprio sistema de saúde. O programa evidencia, assim, a necessidade de ações especiais, de atendimento especial, para as populações mais carentes.

\subsection{Instrumento de (re)estruturação do SUS}

É evidente o papel do PSF - no início implícito, e depois explícito - de instrumento de reorganização e reestruturação do sistema público de saúde. Pode-se afirmar que o programa foi, primeiro, uma alavanca para a organização dos sistemas locais de saúde, à medida que impôs uma série de pré-requisitos para a assinatura dos convênios (funcionamento do fundo e do conselho municipal de saúde); segundo, funcionou como mecanismo de pressão no processo de descentralização, através da exigência de enquadramento na NOB-93, com vistas ao recebimento dos recursos; terceiro, teve papel fundamental na mudança dos critérios de pagamento do sistema, resultando na institucionalização, através da NOB-96 (sobre transferência per capita).

Porém, sua influência não se restringe aos fatos apontados acima: o papel do programa no avanço das formas organizativas da população é também evidente. Para que uma associação da comunidade possa contratar os profissionais do programa, é necessário, em alguns municípios - por exemplo, Niterói - cumprir uma série de formalidades, tais como: registro em cartório, periodicidade e atas de reuniões, balanço financeiro. Desta forma, o programa incentiva mais organização e institucionalidade dos mecanismos de representação da comunidade, aumentando, portanto, as possibilidades de participação e controle da comunidade sobre as ações públicas.

Por último, o programa também é um instrumento de mudança do modelo assistencial, ao evidenciar as fragilidades e limitações do modelo tradicional. A convivência de dois modelos pode ser salutar, em um momento de transição. Porém, como apontam os atuais documentos do programa, no futuro deverá ocorrer 
uma adoção mais homogênea do PSF pelos municípios brasileiros, tendo em vista o próprio sucesso de sua implantação, principalmente em áreas mais carentes.

\subsection{Instrumento de mudanças nas formas e desenho de operação das políticas sociais: novas modalidades de gestão e novos tipos de parceria público/privado}

O PSF introduziu na discussão sobre política social uma série de questões. Primeiro, que é possível haver práticas focalizadas dentro do universalismo e, ao mesmo tempo, dado o caráter de algumas práticas, fazê-las instrumentos de (re)organização da política universal. Segundo, essas novas experiências consolidam o tipo de intervenção proposto pelo Comunidade Solidária, pois não só concretizam o espaço da focalização, como constituem laboratórios de novas modalidades de gestão, que tentam fugir das amarras da gerência pública, estabelecendo, inclusive, novos tipos de parceria com a sociedade.

Nesse programa, os recursos humanos não são contratados como funcionários públicos, mas podem sê-lo por associações da comunidade (o que incentiva a institucionalização e a melhor organização da comunidade). Ao mesmo tempo, os profissionais podem ser remunerados por uma combinação de formas (per capita, procedimentos e produtividade), isto é, pagos por captação mais desempenho ${ }^{27}$. Todos esses elementos inovadores de políticas estão sendo testados pelo programa e podem servir de laboratório de experiências para reformas mais profundas nas formas de operação das políticas sociais.

\section{Lições}

A formulação do PSF teve a seu favor o desenvolvimento anterior de modelos de assistência à família (em Quebec, no Canadá; em Cuba; na Suécia e na Inglaterra), que serviram de guias para a formulação do programa brasileiro. Este é uma adaptação de várias experiências, pois, como bem salientou o ministro Adib Jatene, o Brasil, por ter características próprias, de país continental, não pode obrigar o deslocamento dos médicos (o que é possível em Cuba e na Inglaterra); isto é, exigir que os médicos habitem onde clinicam. Pode, porém, incentivar que esses estejam o mais próximo possível das comunidades que atendem. 
Outro fator importante foi que no momento da formulação do PSF não existia nenhuma proposta concreta de assistência básica para o SUS. A proposta de Sistemas Locais de Saúde (SILOS) ${ }^{28}$ e de distritos de saúde não se impunha como instrumento suficientemente forte no sentido de uma mudança radical das práticas de saúde e do maior impacto dessas ações sobre a população, ou seja, sobre o grau de efetividade dos sistemas locais de saúde. Por outro lado, qualquer programa que tenha por base uma definição de cobertura pode ser um instrumento, uma estratégia de organização das próprias áreas, módulos ou distritos de saúde, como o PSF vem-se mostrando.

Pode-se afirmar, então, que o programa foi formulado num período de "vazio" programático, nos três níveis de governo (federal, estadual e municipal). Nenhuma das instâncias propunha nada de novo e efetivo para o sistema e, cada vez mais, a política seguia numa inércia, repetindo modelos de atendimento antigos e se expandindo em cima de concepções superadas para a área da saúde, sem interlocução, inclusive, com os demais setores da área social. Por outro lado, o Ministério da Saúde tinha consciência de que o SUS avançara pouco no que concerne às estratégias de organização da assistência: como foi dito acima, a proposta de distrito por si só não respondia às inquietações dos gestores municipais. Assim, o sucesso anterior de um outro programa inovador - como foi o dos Agentes Comunitários de Saúde - e o próprio avanço das formas descentralizadas de operação da política de saúde funcionaram como pré-requisitos essenciais para a formulação do PSF.

A fase de formulação se consolida, então, quando da elaboração da NOB-96, que aprofunda o caráter inovador do PSF e explicita uma nova fórmula de cooperação para a operação da política de saúde, envolvendo municípios, pólos, secretarias estaduais e o nível central do Ministério da Saúde. Esses são os elementos facilitadores da implementação do PSF. Porém, o que vem dificultando a expansão do programa?

Em primeiro lugar, a própria estrutura do Ministério da Saúde, que, como se sabe, é extremamente centralizadora, e dificulta, em muitos momentos, um aprofundamento do processo de descentralização. Além de o ministério não ter uma estrutura flexível, é lento do ponto de vista das decisões e não estabelece facilmente pactos de cooperação.

Em segundo lugar está a lenta resposta do aparelho formador de recursos humanos, como foi salientado ao longo deste texto, e as resistências das 
faculdades de Medicina em explorar o campo da Saúde Coletiva e incrementar a formação de médicos generalistas.

Em terceiro vêm as resistências corporativas: as associações de enfermagem (Conselhos e Associação Brasileira de Enfermagem) impõem às atividades dos agentes as mesmas restrições antes impostas às de auxiliar de enfermagem. Da mesma forma, as associações médicas, em especial o Conselho Federal de Medicina $^{29}$, não são favoráveis à formação de médicos generalistas, incentivando a formação de especialidades; e, muitas vezes, os sindicatos médicos são contrários a qualquer tipo de contratação que não seja pela forma de trabalho assalariado.

Em quarto, há a noção de que atenção primária é sinônimo de tecnologia simplificada: na verdade, o PSF introduz uma noção mais sofisticada de atenção primária, tendo em vista que desenvolve todo um instrumental de informática (para diagnóstico e recolhimento dos dados sociais, econômicos e epidemiológicos das populações que pretende cobrir) baseia-se na automação de procedimentos diagnósticos, e se apóia na realização de exames e na utilização de instrumentos - como a ultra-sonografia, podendo utilizar inclusive kitdiagnósticos, como os usados pelos médicos de família cubanos. Dessa forma, a confusão entre atenção primária e tecnologia simplificada amplia o leque de opositores ao programa.

Para finalizar, é importante que se volte, resumidamente, ao início do texto: de que maneira as variáveis selecionadas (exigências econômicas, interesses organizados e dimensão política) influenciaram a formulação do PSF?

Quanto às exigências econômicas, o quadro de crise das finanças públicas e de adoção de políticas de ajuste não é, por si só, um limitador da reforma, e sim um impulsionador de novas modalidades de gestão, economizadoras de custos. Como o programa propõe toda uma reformulação da assistência básica, é de se esperar que o número de internações diminua e que os equipamentos mais sofisticados - como os hospitais terciários e quaternários - possam se dedicar ao atendimento de suas especialidades, o que pode influir em diminuição do gasto de internação hospitalar. Entretanto, como a resolutividade da assistência básica aumenta os níveis de cobertura do sistema de saúde, pode-se ter um aumento da demanda por internações mais complexas, encarecendo o custo da assistência. 
Assim, se num primeiro momento os constrangimentos de ordem econômica podem ser, favoráveis à adoção de novas práticas, num segundo eles podem ser limitadores da expansão da própria reforma. Quanto aos interesses organizados, a tríade de apoio político criada na formulação do PSF parece ter sido suficientemente forte ao menos para neutralizar os atores contrários à reforma. Em relação à dimensão política, a formulação do PSF ocorre num momento de mudança política, com a eleição de um novo presidente, e é proposto outro tipo de estratégia para a área social, pelo menos para as faixas mais carentes da população, como o Programa Comunidade Solidária. Como vimos, este foi extremamente importante para a consolidação do programa no próprio ministério, e para o apoio que aquele teve do novo ministro da área. Entretanto, ao final desse governo não há indicações claras de um aprofundamento das reformas, pois os constrangimentos econômicos são crescentes e novas políticas de ajuste econômico se impõem, com reflexos significativos nas finanças públicas ${ }^{30}$.

A atual descentralização do ajuste fiscal (para estados e municípios) e a recentralização de recursos no nível federal constituirão sérias barreiras à continuidade do processo de descentralização. Tal fato pode ocasionar um retrocesso no processo brasileiro de reforma incremental (do SUS), pois esta se apóia no êxito e aprofundamento da política de descentralização.

\section{Desenho Metodológico}

\subsection{Tipo de estudo}

Trata-se de uma avaliação de processo (do processo de implementação do programa), no sentido que estabelece a relação existente entre atividades desenvolvidas pelo PSF e os resultados encontrados, ressaltando-se as condições de desenvolvimento do programa em seus aspectos institucionais.

Avalia-se, também, a eficácia do programa (relação resultados/ objetivos), além de sua eficiência social, isto é, a inserção do programa junto à população adscrita (relação programa/comunidade).

\subsection{O desenho da investigação}

O estudo da fase de implementação do PSF foi realizado com base em estudos de caso, em alguns municípios escolhidos de forma intencional (amostra intencional), de acordo com os seguintes critérios: 
- grau de adesão regional ao programa;

- tamanho do município;

- grau de municipalização.

Grau de adesão regional ao Programa

A definição do grau de adesão regional ao PSF tomou por base a distribuição dos municípios conveniados, segundo as regiões do País, conforme tabela a seguir.

\begin{tabular}{|c|c|c|c|}
\hline Região & $\begin{array}{c}\mathrm{N}^{\circ} \text { de municípios } \\
\text { conveniados }\end{array}$ & $\%$ & $\begin{array}{c}\mathrm{N}^{\circ} \text { de municípios } \\
\text { do estudo }\end{array}$ \\
\hline NE (Nordeste) & 128 & 56 & 2 \\
\hline NO (Norte) & 3 & 1 & 0 \\
\hline $\mathrm{CO}$ (Centro-Oeste) & 2 & 1 & 0 \\
\hline SE (Sudeste) & 72 & 32 & 2 \\
\hline SU (Sul) & 23 & 10 & 1 \\
\hline Total (Brasil) & 228 & 100 & 5 \\
\hline
\end{tabular}

Dessa forma, em função do grau de adesão regional ao PSF, foram escolhidos dois municípios na Região Nordeste, dois na Região Sudeste e um na Região Sul. Essa escolha permite supor que os resultados encontrados possam refletir o grau de adesão das diferentes regiões do País ao programa.

\section{Tamanho de município}

A escolha do tamanho dos municípios para a seleção dos estudos de caso tomou por base a média de habitantes das localidades, segundo a região do País, conforme tabela a seguir.

\begin{tabular}{l|c|c}
\hline \multicolumn{1}{c|}{ Região } & $\begin{array}{c}\text { Média de habitantes por } \\
\text { município segundo região }\end{array}$ & $\begin{array}{c}\text { Tamanho de municípios } \\
\text { do estudo }\end{array}$ \\
\hline NE (Nordeste) & 27.124 & $20-30 \mathrm{mil}$ \\
SE (Sudeste) & 68.245 & $>70 \mathrm{mil}$ \\
SU (Sul) & 21.053 & $<20 \mathrm{mil}$ \\
\hline
\end{tabular}


Segundo o critério adotado, os municípios escolhidos deveriam ter: na Região Nordeste, entre 20 e 30 mil habitantes; na Região Sudeste, mais de 70 mil habitantes e, na Região Sul, menos de 20 mil habitantes. Essa escolha permitiria relacionar o tamanho do município com o tipo de desenvolvimento local do PSF.

\section{Grau de municipalização}

De acordo com a NOB-01, de 1993, aprovada pelo Ministério da Saúde, os municípios no Brasil se distribuem segundo as seguintes condições de municipalização:

\begin{tabular}{c|l}
\hline Condição & \multicolumn{1}{c}{ Forma de gestão dos recursos } \\
\hline Semiplena & $\begin{array}{l}\text { Recebem diretamente todos os recursos federais para a gestão dos } \\
\text { serviços públicos e privados de saúde. }\end{array}$ \\
\hline Parcial & $\begin{array}{l}\text { Recebem parte dos recursos federais para o custeio do sistema } \\
\text { público de saúde. }\end{array}$ \\
\hline Incipiente & $\begin{array}{l}\text { Os recursos federais são repassados para a esfera estadual, que } \\
\text { depois os transfere. }\end{array}$ \\
\hline
\end{tabular}

Essa distribuição permite aferir o grau de autonomia dos municípios na gestão dos sistemas locais de saúde e, portanto, o grau de descentralização ou o tipo de municipalização que ocorre na área da saúde. Assim o estudo incluiu, no mínimo, um município em cada nível de gestão, de forma a correlacionar grau de municipalização e formas de implementação do programa. Os municípios escolhidos foram os seguintes:

- Sudeste - dois municípios com população com mais de 100 mil habitantes: Barbacena (MG) - gestão semiplena, 105.215 habitantes; Cotia (SP) - sem enquadramento, 121.957 habitantes.

- Nordeste - dois municípios com população entre 20 e 50 mil habitantes: Baturité (CE) - gestão semiplena, 28.585 habitantes; Trindade (PE) gestão incipiente, 20.129 habitantes.

- Sul - um município com população menor que 20 mil habitantes: Cocal do Sul (SC) - gestão parcial, 13.066 habitantes. 
Além destes, foram incluídos no estudo os municípios de Niterói (RJ) e de Olinda (PE) e o Projeto de Qualidade Integral em Saúde (Qualis), no município de São Paulo, pela história e referência feita pelos entrevistados sobre essas experiências nas fases de formulação e desenvolvimento do programa.

Em cada um dos municípios foi pesquisado pelo menos um centro de saúde referido ao programa. O trabalho de campo realizou, ainda, entrevistas (questionários semi-estruturados) com os principais atores do programa: coordenador do programa no estado, secretário municipal de Saúde, coordenador do programa no nível local, médico do programa, membro do Conselho Municipal de Saúde (usuário do programa). Foram realizados, ainda, levantamento documental e entrevistas, quando possível, com membros do legislativo vinculados à área da saúde.

\section{Hipóteses de trabalho}

\subsection{Hipótese geral}

As variações no desempenho do programa (eficácia e eficiência social) estão relacionadas com as condições de implantação do mesmo.

\subsection{Hipóteses específicas}

A eficácia e a eficiência social do programa variam em função:

- da interação entre o desenvolvimento local do programa e as políticas estaduais em prol de mudanças nas práticas da assistência básica; e

- da interação entre o modelo de assistência à saúde no nível local (avaliada segundo o porte da rede e a forma de organização dos serviços, estrutura e capacidade administrativa da Secretaria Municipal de Saúde e o papel da comunidade na gestão do sistema), e o desenho e modo de operação do PSF no município.

\subsection{Variáveis e indicadores}

A variável independente selecionada no modelo causal foi a forma ou o tipo de implantação do programa (condições de implementação), ou melhor, as 
características que o programa assume no nível local. A forma (ou tipo) de implantação do programa foi construída ou se baseou:

- primeiro, no grau de interação das instâncias de governo (federal, estadual e municipal) na implementação do programa; e

- segundo, nas características de implantação do programa no nível municipal, isto é, o modo como o programa opera dentro do modelo municipal de saúde.

As variáveis dependentes contempladas no modelo causal foram duas:

- a eficácia, definida como a relação existente entre os resultados obtidos e os objetivos definidos pelo programa; e

- a eficiência social do programa, definida como a relação entre este e a comunidade, ou seja, sua integração com a população adscrita.

Como indicador de eficácia, definiu-se a participação dos procedimentos ambulatoriais do PSF no total de procedimentos ambulatoriais realizados pela rede municipal de saúde. Como indicador de eficiência social, selecionou-se a participação das atividades dos agentes de saúde no total de procedimentos do PSF. Foram definidas, ainda, como variáveis intervenientes: a modalidade de descentralização (gestão incipiente, parcial e semiplena); o porte do município e a localização territorial (estados e regiões).

Quadro 1 - Situação de Implantação do Programa de Saúde da Família

\begin{tabular}{|c|c|c|c|c|}
\hline Município & $\begin{array}{c}\text { População } \\
\text { Total }\end{array}$ & $\begin{array}{c}\text { Gestão } \\
\text { Municipal }\end{array}$ & $\begin{array}{c}\text { Implantação } \\
\text { do PSF }\end{array}$ & $\begin{array}{c}\text { Grau de adesão ao } \\
\text { Programa (\% de } \\
\text { população adscrita) }\end{array}$ \\
\hline Cocal do Sul (SC) & 12.486 & parcial & janeiro/95 & 35,64 \\
\hline Trindade (PE) & 19.521 & incipiente & julho/96 & 40,98 \\
\hline Baturité (CE) & 29.467 & semiplena & junho/94 & 86,20 \\
\hline Barbacena (MG) & 107.810 & semiplena & setembro/94 & 9,27 \\
\hline Cotia (SP) & 126.956 & Sem enquadramento & abril/94 & \\
\hline Olinda (PE) & 349.380 & semiplena & agosto/95 & 38,64 \\
\hline Niterói (RJ) & 450.364 & semiplena & setembro/92 & 9,55 \\
\hline
\end{tabular}

Fonte: Sistema de Informações Ambulatoriais do SUS (SIA-SUS), DATASUS/MS. 


\section{Apresentação de Resultados}

A produção alcançada pelo PSF nos municípios se destaca, comparandose à produção ambulatorial do SUS. Em Trindade, por exemplo, representa praticamente metade de toda a produção registrada, em apenas dois anos de sua implantação. $\mathrm{O}$ fato de este município se encontrar sob condição de gestão incipiente poderia explicar, em parte, a relevância das atividades do PSF. Contudo, mesmo em municípios sob gestão semiplena, com maior grau de complexidade das ações e existência de outros programas, como Baturité e Olinda, a produção do Programa de Saúde da Família assume expressiva importância. Assim, o tipo de gestão (incipiente, parcial ou semiplena) não interfere diretamente com os resultados encontrados. Em Olinda, o programa encontra-se em franca expansão, desde sua implantação há três anos, representando aproximadamente $35 \%$ da produção ambulatorial total alcançada. Apenas neste último ano, o município registrou um incremento de mais de 50\% das atividades do PSF em relação ao ano anterior (quadro 2).

A consolidação do programa exige, ainda, a superação de várias dificuldades, como a composição e manutenção das equipes profissionais. Dificuldades estas que irão interferir diretamente na produção obtida, como nos casos de Baturité e Cocal do Sul. Em Cocal do Sul, os profissionais e agentes comunitários são os mesmos desde o início do programa, há três anos (há apenas uma equipe). Esta ${ }^{31}$ conseguiu alcançar expressivo resultado: sua produção representa $13 \%$ de toda a produção ambulatorial do município. Já em Baturité, embora o Programa de Saúde da Família represente atualmente cerca de $20 \%$ da produção ambulatorial total, é possível observar expressiva redução de sua produção nos últimos dois anos. Desde sua implantação, em 1994 quando representava cerca de $50 \%$ da produção ambulatorial do município -, o PSF vem sofrendo um decréscimo contínuo de suas ações (quadro 2). No mesmo período houve problemas de renovação dos contratos de trabalho dos profissionais, o que implicou dissolução das equipes, que foram recompostas somente alguns meses depois.

As dificuldades para obter bons níveis de produção ficam ainda mais ressaltadas pelos resultados obtidos nos municípios de Barbacena e Cotia. Nos dois casos (sendo Barbacena em gestão semiplena e Cotia sem enquadramento), o PSF não está totalmente consolidado e enfrenta problemas que se expressam na produção, pela descontinuidade das ações. Vale ressaltar que, embora o 
caso de Barbacena apresente elevado incremento abrupto da produção em 1996, os números absolutos são ainda pouco expressivos.

\section{Quadro 2 - Evolução da Produção do Programa de Saúde da Família - julho/94 a dezembro/97 ${ }^{(*)}$}

\begin{tabular}{|c|c|c|c|c|c|}
\hline \multicolumn{2}{|l|}{ Município } & 1994 & 1995 & 1996 & 1997 \\
\hline \multirow[t]{2}{*}{ Cocal do Sul } & (1) & - & $13,57 \%$ & $10,2 \%$ & $12,92 \%$ \\
\hline & (2) & - & - & (-) $34,6 \%$ & (+) $18,07 \%$ \\
\hline \multirow[t]{2}{*}{ Trindade } & (1) & - & - & $40,18 \%$ & $48,76 \%$ \\
\hline & $(2)$ & - & - & - & (+) $17.92 \%$ \\
\hline \multirow[t]{2}{*}{ Baturité } & (1) & $47,68 \%$ & $39,82 \%$ & $34,27 \%$ & $19,28 \%$ \\
\hline & $(2)$ & - & (-) $62,65 \%$ & (-) $28,5 \%$ & (-) $39,35 \%$ \\
\hline \multirow[t]{2}{*}{ Barbacena } & (1) & $0,4 \%$ & $0,18 \%$ & $1,5 \%$ & $2,13 \%$ \\
\hline & (2) & - & (+) $1,84 \%$ & (+) $1.078 \%$ & (+) $22,12 \%$ \\
\hline \multirow[t]{2}{*}{ Cotia } & (1) & $0,21 \%$ & $1,12 \%$ & $0,17 \%$ & $0,16 \%$ \\
\hline & (2) & - & (+) $845,65 \%$ & (-) $84,82 \%$ & (+) $16 \%$ \\
\hline \multirow[t]{2}{*}{ Olinda } & (1) & - & $20,89 \%$ & $25,68 \%$ & $34,08 \%$ \\
\hline & (2) & - & - & (+) $12,06 \%$ & (+) $54,37 \%$ \\
\hline \multirow[t]{2}{*}{ Niterói } & (1) & - & (+) $91,6 \%$ & (+) $84,48 \%$ & (+) $30,99 \%$ \\
\hline & (2) & - & (+) $91,6 \%$ & (+) $84,48 \%$ & (+) $30,99 \%$ \\
\hline
\end{tabular}

Fonte: Sistema de Informações Ambulatoriais do SUS (SAI-SUS), DATASUS/MS. (1) Percentual em relação à Produção Ambulatorial Total do SUS. (2) Incremento Anual. (*) Período considerado para os municípios que implantaram o Programa a partir de 1994. Para os demais, foi calculada a média referente ao respectivo período de implantação.

Em Niterói, a produção alcançada pelo Programa Médico de Família (PMF) também tem pouca repercussão sobre a produção ambulatorial total do município, mas por outras razões. Trata-se de um município com quase $500 \mathrm{mil}$ habitantes, com ótimos indicadores socioeconômicos, em gestão semiplena e provido de ampla e complexa rede de serviços. As atividades do programa concentram-se nas áreas mais carentes, que representam apenas 10\% da população total. Esses fatores explicam sua pequena contribuição para a produção ambulatorial total, mas não interferem no desenvolvimento do programa, que se encontra plenamente consolidado, com incremento positivo constante desde sua implantação. 
A descrição da produção por procedimento (quadro 3) demonstra que Trindade é o município no qual o PSF vem apresentando o melhor rendimento. São executados, em média, por ano, 3,7 procedimentos em saúde da família, por habitante. Se for considerada apenas a população adscrita ao PSF, o resultado é ainda mais impressionante: 9,04 procedimentos por habitante. A produção do PSF no município encontra-se fortemente assentada na atuação dos agentes comunitários de saúde, que realizam 2,58 visitas por habitante da população total, a cada ano, chegando a 6,3 visitas para a população adscrita. Os demais procedimentos também revelam ótimo desempenho. É realizada uma consulta médica para cada habitante adscrito ao programa e quase duas atividades de enfermeiro. Deve, contudo, ser ressaltado o pequeno número de visitas domiciliares feitas por profissionais de nível superior.

Visitas domiciliares (de profissional de nível médio e superior) apresentam boa produção em Barbacena (1, 11/habitante adscrito) e em Niterói (1,24/ habitante adscrito), o que pode ser atribuído à ausência de agentes comunitários no programa. No caso de Niterói, são realizados, ainda, 2,27 procedimentos do PSF por habitante da população adscrita, enquanto em Barbacena este número é de 1,48.

Olinda e Baturité apresentam os melhores resultados depois de Trindade. Em Olinda, o PSF consegue produzir quase sete procedimentos por habitante adscrito, ao ano; enquanto Baturité alcança 3,29. Em relação à população total, os números chegam a 1,42 e 2,84, respectivamente. Os resultados de Olinda são impressionantes, já que o município possui cerca de 350 mil habitantes, contra apenas 30 mil de Baturité. Da mesma forma, a população adscrita ao PSF, em Olinda, chega a 72 mil pessoas, enquanto em Baturité atinge 25.400. Nos dois municípios é expressiva a atuação dos agentes comunitários. Em Baturité, são realizadas quase duas visitas domiciliares pelos agentes, por ano, para cada habitante da população adscrita. Em Olinda, são quase cinco para a população adscrita, o que representa uma para a população total. As visitas domiciliares dos profissionais de nível superior alcançam 0,55/habitantes em Baturité e 1,03 em Olinda.

A única equipe de Cocal do Sul se supera, conseguindo realizar cerca de três procedimentos ao ano, por habitante da população adscrita, o que representa um por habitante da população total. No entanto, como avaliado pela própria equipe do PSF desse município, o reduzido número de agentes 
comunitários para a extensão e população abrangida resulta em reduzido número de visitas domiciliares: menos de uma por habitante adscrito por ano.

\section{Quadro 3 - Indicadores de Produção do Programa de Saúde da Família por procedimentos - julho/94 a dezembro/97 $7^{(*)}$}

\begin{tabular}{|c|c|c|c|c|c|c|c|}
\hline \multicolumn{2}{|c|}{ Município } & $\begin{array}{c}\text { Total de } \\
\text { procedimentos } \\
\text { doPSF }\end{array}$ & $\begin{array}{c}\text { Consulta } \\
\text { médica } \\
\text { PSF }\end{array}$ & $\begin{array}{l}\text { Atividade } \\
\text { enfermeiro } \\
\text { PSF/PACS }\end{array}$ & $\begin{array}{c}\text { Atividade } \\
\text { agente } \\
\text { comunitário } \\
\text { desaúde }\end{array}$ & $\begin{array}{c}\text { Visita } \\
\text { domiciliar } \\
\text { nívelmédioe } \\
\text { superior }\end{array}$ & $\begin{array}{l}\text { Educação } \\
\text { emSaúde }\end{array}$ \\
\hline \multicolumn{2}{|c|}{ Cocal do Sul (1) } & 1,05 & 0,55 & 0,05 & 0,18 & 0,26 & $\ldots$ \\
\hline & (2) & 2,96 & 1,55 & 0,13 & 0,51 & 0,74 & 0,03 \\
\hline \multirow[t]{2}{*}{ Trindade } & (1) & 3,7 & 0,45 & 0,65 & 2,58 & 0,03 & $\ldots$ \\
\hline & (2) & 9,04 & 1,09 & 1,58 & 6,3 & 0,07 & 0,01 \\
\hline \multirow[t]{2}{*}{ Baturité } & (1) & 2,84 & 0,51 & 0,2 & 1,65 & 0,48 & 0 \\
\hline & (2) & 3,29 & 0,6 & 0,23 & 1,9 & 0,55 & 0 \\
\hline \multirow[t]{2}{*}{ Barbacena } & (1) & 0,14 & 0,01 &.. & $\ldots$ & 0,1 & $\ldots$ \\
\hline & (2) & 1,48 & 0,14 & 0,01 & $\ldots$ & 1,11 & $\ldots$ \\
\hline \multirow[t]{2}{*}{ Cotia } & (1) & 0,02 & 0,02 & - & - & 0,01 & $\ldots$ \\
\hline & (2) & - & - & - & - & - & - \\
\hline \multirow[t]{2}{*}{ Olinda } & (1) & 1,42 & 0,09 & 0,12 & 0,99 & 0,21 & $\ldots$ \\
\hline & (2) & $.6,91$ & 0,46 & 0,59 & 4,79 & 1,03 & 0,04 \\
\hline \multirow[t]{2}{*}{ Niterói } & (1) & 0,22 & 0,08 & - & $\ldots$ & 0,12 & 0,02 \\
\hline & (2) & 2,27 & 0,84 & - & $\ldots$ & 1,24 & 0,19 \\
\hline
\end{tabular}

Fonte: Sistema de Informações Ambulatoriais do SUS (SAI-SUS), DATASUS/MS. (1) Média de procedimentos realizados em relação à população total. (2) Média de procedimentos realizados em relação à população adscrita. ${ }^{(*)}$ Período considerado para os municípios que implantaram o Programa a partir de 1994. Para os demais, foi calculada a média referente ao respectivo período de implantação.

Os resultados encontrados (análise quantitativa) e a análise qualitativa da implantação do PSF nos sete municípios da pesquisa (os estudos de caso) permitem identificar três modelos de implantação do programa (DAL POZ, 1998; VIANA, 1998; BRANCO, 1998; FORMIGA e BRANCO, 1998). Esses modelos se relacionam com os próprios resultados (de produção) encontrados, com o grau de adesão regional ao programa, com o funcionamento do sistema 
local de saúde e com os atores políticos presentes na sustentação do programa (sua base social).

Os modelos podem ser assim denominados: Modelo Regional de Implantação do Programa de Saúde da Família (MR); Modelo Singular de Implantação do Programa de Saúde da Família (MS) e Modelo Principiante de Implantação do Programa de Saúde da Família (MP).

O primeiro modelo se caracteriza pelo desenvolvimento regional do programa, isto é, o programa no nível local é fortemente influenciado por uma política regional (estadual) de apoio às mudanças nas práticas assistenciais de saúde, em específico na área ambulatorial (atenção primária). No modelo regional, o estado desenvolve vários programas na área de saúde - principalmente para prevenção e atenção básica - que produzem efeitos sinérgicos, reforçandose mutuamente e criando capacidades institucionais para a gestão de novos programas de caráter inovador. Além disso, desenvolvem também programas e espaços institucionais intersetoriais na área social (como no estado do Ceará), onde a figura do agente extrapola a questão da saúde e passa a ser a "porta de entrada" das políticas sociais para as populações mais carentes (TENDLER, 1997). Esse modelo conta ainda com grande apoio e participação da comunidade. A população atua tanto através dos seus canais (próprios) de representação (associações e sindicatos), quanto nas instâncias de gestão do sistema (conselhos gestores de unidades de saúde e conselho municipal de saúde).

Os casos dos municípios do Nordeste correspondem a esse modelo, onde o PSF foi precedido por outros programas inovadores (PACS, no Ceará e Pernambuco; Salva-Vidas, em Pernambuco). A influência da política estadual de saúde se reflete tanto no modelo municipal de saúde (avanço da descentralização municipalizante) - tendo em vista que os três municípios do Nordeste estão enquadrados na NOB-93, sendo dois em gestão semiplena e um em gestão incipiente - quanto no desenvolvimento pioneiro, como no estado do Ceará, do Programa de Agentes Comunitários de Saúde, ou de outros programas de fomento à atenção básica. Além disso, em alguns estados já se desenvolvem políticas intersetoriais na área social, como no Ceará (através dos Conselhos de Desenvolvimento Sustentável). Cabe ressaltar que nessa mesma região há o maior grau de adesão ao programa (no Ceará, quase 50\% dos municípios estão implantando o PSF). 


\section{Quadro 4 - Modelo Regional de Implantação do PSF}

\begin{tabular}{|c|c|c|c|c|c|c|}
\hline Município & População $^{\mathbf{3 2}}$ & Gestão & Região & Adesão Regional $^{\mathbf{3 3}}$ & Resultado $^{\mathbf{3 4}}$ & Atores $^{\mathbf{3 5}}$ \\
\hline Baturité & pequeno & semiplena & Nordeste & alta & ótimo & $5,2,1$ \\
\hline Trindade & pequeno & incipiente & Nordeste & alta & ótimo & $5,2,1$ \\
\hline Olinda & médio & semiplena & Nordeste & alta & ótimo & $5,2,1$ \\
\hline
\end{tabular}

Fonte: Elaboração pesquisa.

Assim, Baturité, Trindade e Olinda são exemplos desse modelo, com algumas diferenças importantes no que diz respeito ao tamanho do município: os dois primeiros são pequenos, enquanto Olinda é de médio porte. Excluindo essa diferença, os três não fogem às caracterizações mais gerais do modelo, apontadas mais acima. Portanto, o tamanho do município não constitui variável explicativa e não interfere diretamente no resultado encontrado. Nesse primeiro modelo são atores importantes: a Secretaria Estadual de Saúde (os secretários estaduais), os prefeitos municipais e a comunidade. Os profissionais não são peça decisiva na definição dos rumos do programa (em alguns casos, como em Baturité, os médicos mais jovens não se sentem atraídos pelo programa). A oposição ao programa desenvolve-se dentro dos centros de maior referência (hospitais e clínicas privadas). No quadro 4 podem-se observar: as relações positivas que se estabelecem entre a região geográfica (e seu grau de adesão ao programa), os resultados de produção (\% de procedimentos do PSF sobre o total de procedimentos ambulatoriais do município) e os atores mais relevantes de apoio ao programa.

O segundo modelo é aquele que desenvolve uma experiência singular - Modelo Singular de Implantação do PSF -, sem envolvimento das outras esferas de governo. Esses são os casos de Niterói, Cocal do Sul e do Projeto Qualis, no município de São Paulo. O modelo é autônomo, envolvendo a própria estrutura da Secretaria Municipal de Saúde (Niterói e Cocal do Sul), ou uma instituição privada (Qualis). 
Quadro 5 - Modelo Singular de Implantação do PSF

\begin{tabular}{|c|c|c|c|c|c|c|}
\hline Município & População $^{\mathbf{3 6}}$ & Gestão & Região & $\begin{array}{c}\text { Adesão } \\
\text { Regional }^{37}\end{array}$ & Resultado $^{\mathbf{3 8}}$ & Atores $^{\mathbf{3 9}}$ \\
\hline Niterói & grande & semiplena & Sudeste & média & baixo & $5,2,4$ \\
\hline Qualis & grande & - & Sudeste & média & - & 2,9 \\
\hline Cocal & pequeno & parcial & Sul & baixa & bom & $5,7,4$ \\
\hline
\end{tabular}

Fonte: Elaboração pesquisa.

São municípios ou áreas que implantam modelos-piloto, inseridos na história sanitária municipal (Niterói) ou da instituição gestora do programa (Hospital Santa Marcelina, no caso do Qualis). Esse hospital já desenvolvia um modelo de saúde que integrava a rede básica a ele próprio, com a presença de agentes comunitários de saúde. O caso de Cocal do Sul revela uma experiência que tenm por base o êxito do programa de agentes da Pastoral de Saúde (entidade da Igreja católica), com forte influência do modelo cubano de médico de família. Esse modelo também é fortemente influenciado pelas comunidades locais, cuja participação é decisiva para o bom êxito do programa. O quadro 5 apresenta os municípios incluídos nesse modelo, o grau de adesão regional, os resultados alcançados e os atores. Cabe salientar que os tipos de atores sustentadores das atividades do programa (secretário municipal, comunidade, entidade filantrópica ou técnicos externos) compensam o baixo envolvimento da esfera regional com a implantação local do PSF.

O terceiro modelo é representado pelos casos de Barbacena e Cotia, onde o programa ainda é incerto, pouco desenvolvido, sem participação da comunidade, e se desenvolve de forma isolada, tanto das demais instâncias de governo, como da própria comunidade. Isso resulta em alta centralização das decisões sobre a política de saúde e contribui para o desenvolvimento de estruturas gestoras altamente centralizadas e verticalizadas, o que reforça, ainda mais, a centralização das decisões políticas. Em Barbacena o PSF está mais desenvolvido do que em Cotia, porque conta com o apoio de técnicos do programa de Niterói e dos médicos de família cubanos. Porém, Barbacena não possui uma rede básica suficiente e bem aparelhada para desenvolver o programa; Cotia, ao contrário, possui essa rede, mas não conta com nenhuma 
ajuda externa (de outra instância de governo ou de técnicos e/ou médicos de outro município ou país). O quadro 6 mostra os municípios incluídos no modelo e as relações entre adesão, resultados e atores.

\section{Quadro 6 - Modelo Principiante de Implantação do PSF}

\begin{tabular}{|c|c|c|c|c|c|c|}
\hline Município & População $^{40}$ & Gestão & Região & $\begin{array}{c}\text { Adesão } \\
\text { Regional }^{41}\end{array}$ & Resultado $^{\mathbf{4 2}}$ & Atores $^{\mathbf{4 3}}$ \\
\hline Cotia & médio & s/enquadramento & Sudeste & média & baixo & 5 \\
\hline Barbacena & médio & semiplena & Sudeste & média & baixo & 5,4 \\
\hline
\end{tabular}

Fonte: Elaboração pesquisa.

\section{Conclusão e Discussão}

É interessante perceber como os modelos se relacionam com os resultados: no Modelo Regional o programa possui uma forte presença na produção ambulatorial total do município (o programa tende a absorver quase metade do total de procedimentos ambulatoriais) e é expressiva a atividade do agente. Isso mostra como é importante a participação das outras instâncias de governo (principalmente da instância regional) e do desenvolvimento conjunto de outros programas inovadores. Um programa é considerado inovador quando introduz outros tipos de profissionais e outro tipo de atividades na assistência à saúde, outras formas de relacionamento com a comunidade e, além disso, explora novos tipos de contratação de profissionais.

Nos estados do Nordeste houve o melhor desenvolvimento do Programa de Agentes Comunitários de Saúde. É onde também o PSF está mais bem implantado, através de políticas estaduais de apoio. Assim, explica-se por que os indicadores de produção são, nos municípios estudados, nessa região, superiores àqueles encontrados em outras regiões. O apoio e a participação da comunidade são intensos, o que é incentivado pelo executivo local. Isso pode ser visualizado pelo número de atividades do agente comunitário de saúde frente ao total de procedimentos do PSF. Ressalte-se, ainda, a forte presença dos Secretários Municipais de Saúde nas formulações de políticas estaduais e no desenvolvimento de iniciativas pioneiras na área da atenção básica. São os 
agentes, nesses municípios, que têm maior envolvimento com o programa e dão o "rosto" ao PSF: os agentes estão em contato direto com a comunidade e são a novidade na atenção básica.

O segundo modelo - Modelo Singular - revela que é possível desenvolver o programa quando há alguma estrutura ou instituição que possa liderar o processo de implantação, independentemente das situações do entorno. Por exemplo, Niterói é um caso isolado no Estado do Rio de Janeiro, e o Projeto Qualis desenvolve-se no município de São Paulo, onde há mais de um modelo de saúde, além de uma situação atípica, na qual poucos serviços foram municipalizados e a prefeitura iniciou um modelo de cooperativas para a área da saúde - Plano de Atendimento à Saúde (PAS). Quando há instituições dispostas a gerenciar, com experiências semelhantes na área, é possível desenvolver $o$ programa, tendo em vista que em áreas populosas ele representará entre 10 e $20 \%$ do total de procedimentos ambulatoriais, isto é, ele necessariamente irá conviver com outros modelos de saúde.

O terceiro modelo indica que quando não há essa instituição gerente e o apoio de outras instâncias - além da participação da comunidade - é quase impossível o desenvolvimento de um programa do tipo do PSF, mesmo com uma rede física adequada (como é o caso de Cotia). O programa, em Barbacena, não conta com uma rede adequada, porém há apoio externo. Isso revela que o apoio da comunidade e sua disposição de legitimar e se envolver com o programa são uma variável-chave para a implementação do PSF.

Quanto aos problemas que o programa enfrenta para sua implantação, o mais relevante é a ausência das demais esferas de governo (estadual e federal) no auxílio ao seu desenvolvimento ${ }^{44}$. Por outro lado, seria desejável que se expandissem iniciativas intermunicipais e, na área municipal, fossem criados espaços intersetoriais, pois o PSF é um instrumento poderoso para a emergência de ações intersetoriais na área social: o agente pode acionar outras estruturas municipais quando vê que o problema à sua frente decorre de fatores externos à área da saúde.

O segundo problema mais relevante é a carência de recursos humanos, principalmente na área médica, o que vem sendo resolvido com a utilização dos médicos cubanos, porém restrito a algumas áreas do País. Os pólos de capacitação, entretanto, devem apresentar uma solução a curto prazo. É interessante ressaltar a ausência de reclamações quanto ao financiamento do programa $^{45}$, tendo sido ressaltado que a implantação do PAB ocasionará um 
reforço financeiro considerável. Os estados estão suplementando os gastos, principalmente na área de medicamentos, tendo sido apontado pelos entrevistados que o SUS só financia cerca de $40 \%$ dos custos do programa, sendo o restante financiado pelos estados e municípios.

Por último, cabe sublinhar que o programa ainda não possui um bom grau de integração com os demais programas operados pelas secretarias municipais de Saúde e com as unidades de saúde, de acordo com os estudos de caso da pesquisa ${ }^{46}$. Assim, a análise dessas experiências é ainda limitada e indica que o desenvolvimento regional de programas é ainda um forte modelo de fomento às ações da área social, ao lado do estímulo à participação da comunidade. O PSF pode ser adequado para algumas áreas, o que não exclui outras formas de implantação, como a implementada de forma singular e isolada, quando há condições institucionais, inclusive através da utilização de associações privadas filantrópicas. É um desperdício de recursos o uso do programa de forma incipiente e anárquica, como uma atividade a mais, sem inclusão em algum plano, projeto ou meta regional e/ou local de melhoria das condições de saúde da população.

\section{Referências}

BJÖRKMAN, J.W.; ALTENSTETIER, C. Globalized concepts and localized practice: convergence and divergence in national health policy reforms. In: ALTENSTETIER, C.; BJÖRKMAN, J.W. (Ed.). Health policy reform, national variations and globalization. London: McMillan Press, 1997.

BRANCO, M. A Reforma em Saúde no Brasil. Programa de Saúde da Família: a experiência de Olinda e Trindade. In: VIANA, A. L.; DAL POZ, M. R. (Coord.). Reforma em Saúde no Brasil. Rio de Janeiro: IMS/UERJ, 1998 (Série Estudos em Saúde Coletiva, 165).

BRASIL. Ministério da Saúde. Programa de Saúde da Família: saúde dentro de casa. Brasília: Fundação Nacional de Saúde, 1994.

BRASIL. Ministério da Saúde. Saúde da Família: uma estratégia de organização dos serviços de saúde. Brasília: Secretaria de Assistência à Saúde, 1996.

DAL POZ, M. R. Reforma em Saúde no Brasil. Programa de Saúde da Família: a experiência de Baturité. In: VIANA, A L.; DAL POZ, M. R. (Coord.). 
Reforma em Saúde no Brasil. Rio de Janeiro: IMS/UERJ, 1998 (Série Estudos em Saúde Coletiva, 162).

FORMIGA C.; BRANCO, M. A. Reforma em Saúde no Brasil. Programa de Saúde da Família: a experiência de Cocal do Sul. In: VIANA, A. L.; DAL POZ, M. R. (Coord.). Reforma em Saúde no Brasil. Rio de Janeiro: IMS/ UERJ, 1998 (Série Estudos em Saúde Coletiva, 164).

FORMIGA C. e BRANCO, M. A. Reforma em Saúde no Brasil. Programa de Saúde da Família: a experiência de Barbacena. In: VIANA, A. L.; DAL POZ, M. R. (Coord.). Reforma em Saúde no Brasil. Rio de Janeiro: IMS/UERJ, 1998 (Série Estudos em Saúde Coletiva, 163).

FRANCE, G. Introduzione. La Sanità in trasformazione. L'Assistenza Sociale. Rivista Trimestralle sulle Prospettive del Welfare. Roma, s/p, 1997.

MELLO, M. A Reformando a reforma: interesses, atores e instituições da Seguridade Social no Brasil. São Paulo em Perspectiva. São Paulo, v. 10, n. 4, 1996.

PATARRA, N. L. Mudança na dinâmica demográfica. In: MONTEIRO, C. A. (Org.). Velhos e novos males da saúde no Brasil. São Paulo: Hucitec, 1995. TENDLER, J. Good government in the tropics. Baltimore: The Johns Hopkins University Press, 1997.

VIANA, A L. Reforma em Saúde no Brasil. Análise da Formulação e Implementação do Programa,de Saúde da Família: a experiência de Cotia. In: VIANA, A. L.; DAL POZ, M. R. (Coord.). Reforma em Saúde no Brasil. Rio de Janeiro: IMS/UERJ, 1998 (Série Estudos em Saúde Coletiva, 161). 


\section{NOTAS}

${ }^{1}$ Este trabalho foi financiado e realizado no âmbito do programa Procesos de Reforma en Educación y Sa lu d. Diseno. Implementación y Grupos de lnterés, patrocinado pelo Banco Interamericano de Desenvolvimento (BID) e pelo Centro Internacional de Investigações para o Desenvolvimento (CIID-IRDC), coordenado pelo Centro de Investigacióne DesarrolIo de Ia Educación (CIDE) e pelo Instituto Latinoamericano de Doctrina y Estudios Sociales (ILADES). Publicado em Physis, v. 8, n. 2, 1998.

${ }^{2}$ Professora Adjunta do Departamento de Medicina Preventiva da Universidade de São Paulo. E-mail: anaviana@usp.br

${ }^{3}$ Professor Adjunto do Departamento de Planejamento e Administração em Saúde do IMS/ UERJ. E-mail: dalpozm@who.int

${ }^{4}$ Os autores agradecem os valiosos comentários que Cristian Aedo. Aristides Torche e Heloísa Machado de Souza fizeram sobre a versão original deste texto.

${ }^{5} \mathrm{O}$ texto sobre saúde faz parte do capítulo sobre seguridade social, em que as ações da área social (saúde, previdência e assistência) são de caráter universal (direito do cidadão/obrigação do Estado), com orçamento único (para a área da seguridade), composto por contribuições sociais. São criados, nesse período, novos tipos de contribuições sociais, como a contribuição sobre o lucro das empresas e recursos fiscais.

${ }^{6}$ Em artigos recentes são empregados os termos reforma da reforma ou reformando a reforma. Ver: Mello (1996).

${ }^{7}$ As reformas dos sistemas de saúde decorrem de uma conjuntura que produz custos crescentes (na área da saúde) frente a uma redução da capacidade financeira dos Estados nacionais para financiar as ações de saúde e a quebra das bases de solidariedade criadas para a cobertura dos riscos clássicos, como a doença.

${ }^{8}$ Ver, por exemplo, a reforma no sistema de saúde de Québec (Canadá), que definiu o foco da ação governamental nos cidadãos, seja como consumidores, financiadores ou tomadores de decisão.

${ }^{9}$ O PACS e o PSF têm início antes de 1995 (o PACS , em 1991, e o PSF, em 1994), porém sua expansão nacional ocorre a partir de 1995, como será visto ao longo da análise do processo de formulação do programa.

${ }^{10}$ Cabe salientar que a NOB-96 começa a ser implantada somente em 1998. 
${ }^{11}$ Foram entrevistados: Dr. Adib Jatene (ministro da Saúde de janeiro de 1995 a março de 1997); Dr. Eduardo Levcovitz (secretário de Assistência à Saúde, de janeiro de 1995 a julho de 1997); Dr. José Paranaguá de Santana (consultor da Organização Pan-americana da Saúde - OPAS); Dr. Eugênio Villaça Mendes (ex-consultor da OPAS); Heloísa Machado (coordenadora do Programa de Saúde da Família no Ministério da Saúde); Dr. Luís Odorico (ex-secretário municipal de Saúde de Quixadá, Ceará); Dra. Ana Maria Cavalcante (ex-secretária estadual de Saúde do Ceará); Dr. Hésio Cordeiro (consultor do Programa de Saúde da Família); Anna Maria Peliano (secretária executiva do Programa Comunidade Solidária).

${ }^{12}$ Cabe assinalar que, antes da reunião de dezembro, consultores da OPAS e do UNICEF, a pedido do então secretário municipal de Saúde de Quixadá, dr. Luiz Odorico, estiveram reunidos para discutir uma nova proposta para a atenção básica, que incorporasse recursos médicos e de enfermagem (dados os limites do PACS). Participaram dessa reunião: Eugênio Villaça Mendes (OPAS); Oscar Castillo (UNICEF); Halim Antônio Girade (UNICEF); Luís Odorico (secretário municipal de Saúde de Quixadá).

${ }^{13}$ A idéia de supervisão do trabalho do agente por um profissional de enfermagem já constava do Programa Estadual de Agentes Comunitários de Saúde do Estado do Ceará, não estando porém implementado. O enfermeiro passa a ser o supervisor no programa nesse estado quando das primeiras avaliações sobre o programa, que evidenciavam as dificuldades de resolução dos problemas trazidos pelo agente, devido à não-existência de profissional de nível superior.

${ }^{14}$ Nesse documento são definidos ainda: a área de abrangência do programa (800 a 1.000 famílias por equipe, formada por um médico, um enfermeiro, um auxiliar de enfermagem e quatro a seis agentes comunitários); a forma de remuneração da equipe (de forma diferenciada quanto aos demais profissionais do SUS); o regime de trabalho (dedicação exclusiva e residência na própria área de atuação); o âmbito da atenção (atenção integral e contínua a todos os membros de cada família, além da atenção à demanda espontânea organizada e gerada pelas ações educativas e coletivas); e o controle social (pelos conselhos de saúde). No mesmo documento são ainda definidas as atividades do programa: diagnóstico de saúde da comunidade, visita domiciliar, internação domiciliar, participação em grupos comunitários, atendimento nas unidades e estabelecimento de referência e contra-referência. As metas, definidas pelo documento, são constituir e capacitar 2.500 equipes e beneficiar 2,5 milhões de famílias. Os recursos do convênio devem corresponder aos gastos de custeio do programa nos primeiros três meses de funcionamento e de alguns itens de investimento (calculado em $\mathrm{R} \$ 30 \mathrm{mil}$ ). Cabe salientar que, na implantação da NOB-93, de forma informal e como um acerto político - sem estar, portanto, normatizado - foi destinado um teto especial para os municípios que estivessem operando o PSF. 
${ }^{15}$ O Programa Metropolitano de Saúde foi formulado no final da década de 70 e sua implantação data de 1983. Destinava-se à área metropolitana da cidade de São Paulo e envolvia a formação de cinco módulos de saúde (com autonomia gerencial e um modelo de atenção integral à saúde), e realização de novos investimentos (construção e reforma de centros de saúde e hospitais), com recursos externos (empréstimo do Banco Mundial) e internos.

${ }^{16}$ Os convênios ainda foram mantidos, a partir dessa data, para financiamento da compra de veículos e equipamentos (para alguns estados e municípios).

${ }^{17}$ Cabe salientar que, desde 1994, quando da gestão do ministro Henrique Santillo, já estava definido o pagamento por procedimentos (SAI-SUS) ao PSF, inclusive o diferencial (duas vezes a consulta SUS) para o programa, conforme relato dos entrevistados.

${ }^{18}$ Os procedimentos remunerados pelo SAI-SUS para o PSF até o momento são: consultas médicas, pequenas cirurgias, visita domiciliar de profissional de nível superior, trabalho de grupo por nível superior, atividade de enfermeiro, procedimentos de enfermagem, visita domiciliar de nível médio, trabalho de grupo por nível médio, visita domiciliar do agente comunitário de saúde e ECS (educação e comunicação em saúde).

${ }^{19}$ A NOB-93 propõe três tipos de habilitação para os municípios: incipiente, parcial e semiplena. As mesmas constituem passos intermediários no processo de descentralização, no qual a categoria semiplena corresponde à gestão autônoma dos recursos de saúde no nível municipal.

${ }^{20}$ Portaria ${ }^{\circ} 8$, de 12 de janeiro de 1996

${ }^{21}$ Portaria $\mathrm{n}^{\circ} 157$, de 19 de fevereiro de 1998. Fixa os valores a serem pagos aos municípios por equipe implantada do PSF, que variarão segundo os valores da parte fixa do PAB, da seguinte forma: municípios com parte fixa do PAB maior ou igual a $\mathrm{R} \$ 10$ e menor que $\mathrm{R} \$ 12$ - incentivo de R \$ 21 mil por ano (por equipe); municípios com parte fixa do PAB maior ou igual a R\$ 12 e menor que R \$ 14 - incentivo de R \$ 19 mil; municípios com parte fixa do PAB maior ou igual a \$ 14 e menor que R\$ 16 - incentivo de $\mathrm{R} \$ 15$ mil.

${ }^{22}$ Portaria $\mathrm{n}^{\circ} 157$, de 19 de fevereiro de 1998.

${ }^{23}$ Portaria ${ }^{\circ} 2.090$, de 26 de fevereiro de 1998

${ }^{24}$ Foram formados dez pólos de capacitação, seis como projetos de capacitação com potencial de pólo e cinco propostas de cursos. Em médio prazo, em todo o Brasil, serão constituídos 21 projetos (capitaneados pelas secretarias estaduais, com apoio de órgãos universitários). Os pólos devem formar os recursos humanos necessários para a expansão do PSF, de forma que o sistema de formação esteja mais próximo do desenho do sistema de saúde, isto é, que se crie um 
mercado de trabalho compatível com a produção de um novo tipo de profissional. Cabe salientar que os pólos são também financiados pelo REFORSUS.

${ }^{25}$ Atualmente, 1.600 equipes estão implantando esses pólos em todo o território nacional.

${ }^{26}$ O Programa Comunidade Solidária foi criado no início do Governo Fernando Henrique Cardoso como uma estratégia de articulação de programas sociais voltados para as populações mais carentes. Funciona na forma de uma secretaria executiva, ligada diretamente ao Gabinete Civil da Presidência da República, e se apóia em um conselho de experts na área social.

${ }^{27}$ Nos estudos de caso apareceram formas variadas de contratação e remuneração de profissionais: em Cocal do Sul, todos os profissionais do PSF de nível superior são funcionários públicos, enquanto os agentes comunitários de saúde são contratados como prestadores de serviço, através de uma cooperativa; nos demais municípios, todos os profissionais que atuam no PSF são contratados como prestadores de serviço. Essa contratação é feita através da própria Secretaria Municipal de Saúde (nos municípios de Trindade, Barbacena e Baturité), de cooperativas (em Olinda), de associações de moradores (Niterói) e até mesmo de empresas privadas (Cotia). As formas de remuneração também são variadas e os regimes de trabalho não são sempre de 40 horas semanais, conforme é indicado pelo programa. Assinale-se, por fim, que os salários pagos às equipes do PSF representam, em geral, o dobro, ou até mais, do que é pago aos demais servidores municipais nas respectivas categorias profissionais.

${ }^{28}$ Nos termos propostos pela Organização Pan-americana da Saúde.

${ }^{29} \mathrm{O}$ presidente do Conselho Federal de Medicina, segundo um dos entrevistados, se opunha ao programa, com receio de que o mesmo subtraísse mercado de trabalho dos médicos.

${ }^{30}$ A questão do financiamento para as ações de saúde ainda estava pendente (negociava-se a prorrogação da CPMF) e, em entrevistas a periódicos, o então Ministro da Saúde (José Serra) se dizia favorável à fixação tanto do teto de contribuição dos recursos do orçamento da Seguridade para a Saúde, quanto da participação dos estados e municípios no gasto (público) em saúde (Projeto de Emenda Constitucional n 169).

${ }^{31}$ Composta de um médico, um enfermeiro, dois auxiliares de enfermagem e apenas dois agentes comunitários, é responsável pelo atendimento de mais de 1.000 famílias em dois bairros, totalizando cerca de 4.500 habitantes, o que representa 35,64\% da população total do município.

${ }^{32}$ Tamanho de município: 70 até 500 mil, médio; <70 mil, pequeno; > 500 mil, grande.

${ }^{33}$ Adesão: >50\%, grande; $20-50 \%$, média; <20\% baixa.

${ }^{34}$ Resultado: $>30 \%$, ótimo; $10-30 \%$ bom; $<10 \%$, baixo (quadro 2). 
A Reforma do Sistema de Saúde no Brasil...

35 (1) SES (secretário estadual de Saúde) / (2) Comunidade (Associações) / (3) Profissionais (Médico/ Enfermagem/Agente) / (4) Técnicos e médicos externos (Niterói, Cuba) / (5) Prefeito (secretário municipal de Saúde) / (6) MS (Ministério da Saúde) / (7) Igreja (Pastoral da Saúde) / (8) Conselhos da Saúde (Conselhos Gestores/CMS) / (9) Associações Filantrópicas.

${ }^{36}$ Tamanho de município: 70 até 500 mil, médio; <70 mil, pequeno; > 500 mil, grande.

${ }^{37}$ Adesão: >50\%, grande; 20-50\%, média; <20\% baixa.

${ }^{38}$ Resultado: >30\%, ótimo; $10-30 \%$ bom; <10\%, baixo (quadro 2).

39 (1) SES (secretário estadual de Saúde) / (2) Comunidade (Associações) / (3) Profissionais (Médico/ Enfermagem/Agente) / (4) Técnicos e médicos externos (Niterói, Cuba) / (5) Prefeito (secretário municipal de Saúde) / (6) MS (Ministério da Saúde) / (7) Igreja (Pastoral da Saúde) / (8) Conselhos da Saúde (Conselhos Gestores/CMS) / (9) Associações Filantrópicas.

${ }^{40}$ Tamanho de município: 70 até 500 mil, médio; <70 mil, pequeno; > 500 mil, grande.

${ }^{41}$ Adesão: >50\%, grande; 20-50\%, média; <20\% baixa.

${ }^{42}$ Resultado: $>30 \%$, ótimo; $10-30 \%$ bom; $<10 \%$, baixo (quadro 2).

43 (1) SES (secretário estadual de Saúde) / (2) Comunidade (Associações) / (3) Profissionais (Médico/Enfermagem/Agente) / (4) Técnicos e médicos externos (Niterói, Cuba) / (5) Prefeito (secretário municipal de Saúde) / (6) MS (Ministério da Saúde) / (7) Igreja (Pastoral da Saúde) / (8) Conselhos da Saúde (Conselhos Gestores/CMS) / (9) Associações Filantrópicas.

${ }^{44}$ A presença do Ministério da Saúde pouco se faz sentir nos municípios estudados pela pesquisa. Em Barbacena, Olinda e Baturité, foi relatada alguma atuação, ligada às atividades de capacitação; em Barbacena, de apoio logístico e orientações; em Olinda, de cooperação técnica.

${ }^{45}$ Em Niterói, o custo mensal per capita do programa é de oito reais, bem abaixo do custo do PAS (Plano de Atendimento à Saúde), e em São Paulo fica em torno de doze reais - acima dos gastos per capita do SUS e das indicações do Banco Mundial para os gastos com pacote ou cesta básica de assistência (cerca de dois reais).

${ }^{46}$ Em Niterói e Barbacena, o PSF melhor se integra com os demais programas de saúde e com as unidades de saúde: em Barbacena foram definidas quotas de utilização de consultas especializadas, exames e internações; em Niterói, o programa está inserido no sistema de referência. Ambos implantaram central de marcação de consultas para gerenciar as demandas do PSF. 


\section{ABSTRACT}

The Reorganization of the Brazilian Health System, and the Family Health Program

The text examines the genesis of the Family Health Program, identifying the formulation and implementation strategies and progress indicators aiming at learning the lessons that may help improve Brazilian health policies. Three models of program implementation were identified: a Regional Model, a Singular Model and a Beginner's Model. The first is characterized by the regional development of the program, and is strongly influenced by a state policy of support for change in the health care practice; the second developed a singular experience, without involvement of any other government authority; and the third model is developed in an incipient and uncertain way.

Key words: Health Family Program; health reform; public policy. 